\title{
Development and application of patient decision aids
}

\author{
Jong-Myon Bae \\ Department of Preventive Medicine, Jeju National University School of Medicine, Jeju, Korea
}

\begin{abstract}
With the current overdiagnosis of thyroid cancer resulting from routine screening in Korea, it is necessary to educate the public that not all cancers are malignant. The exposure to patient decision aids (PtDAs) compared to usual care reduced the number of people choosing to undergo prostate-specific antigen screening. This article introduces the definition, usefulness, and developmental processes of PtDAs and suggests the urgent need for a Korean PtDA related to thyroid cancer screening.
\end{abstract}

KEY WORDS: Decision aids, Thyroid neoplasms, Early detection of cancer, Clinical decision support systems

\section{INTRODUCTION}

An article published in a renowned international journal in 2014 [1] that raised concerns about overdiagnosis for thyroid cancer screening caused great waves of public anxiety at home and abroad. This study advanced a claim that ultrasonography screening is responsible for the rapid increase in the thyroid cancer incidence, placing it at the top of the list [2] without contributing to a reduction in mortality [3] and interpreted it as overdiagnosis through the unnecessary use of ultrasonography screening [1]. On a related note, an unfounded claim that the increase in thyroid cancer rates among women living near nuclear power plants is ascribable to the exposure to radiation [4] has been causing concerns across the country [5].

Debates over overdiagnosis in the screening process also surround prostate cancer, breast cancer, and skin melanoma $[3,6]$. One good example is the rapid increase in the incidence rate of prostate cancer in North America in early 2000 with the advent of prostate-specific antigen (PSA) testing in clinical screening settings [7]. The efforts made to solve the dilemma and over-

Correspondence: Jong-Myon Bae

Department of Preventive Medicine, Jeju National University School of

Medicine, 102 Jejudaehak-ro, Jeju 690-756, Korea

Tel: +82-64-755-5567, Fax: +82-64-725-2593, E-mail: jmbae@cheju.ac.kr

Received: Jan 8, 2015, Accepted: Apr 2, 2015, Published: Apr 8, 2015

This article is available from: http://e-epih.org/

(C) 2015, Korean Society of Epidemiology

(C) This is an open-access article distributed under the terms of the Creative Commons Attribution License (http://creativecommons.org/licenses/by/3.0/), which permits unrestricted use, distribution, and reproduction in any medium, provided the original work is properly cited. come related controversies are significant as events that provide the opportunity for review and reflection [8]. Especially, Esserman \& Thompson [8] emphasized the absolute necessity for vulnerable group education about screening adequacy. Despite the diagnostic principle that specific cancer screening testing is not recommended for the general population [9], this principle cannot be always respected in the face of the fear of those with wishing to be examined [10,11]. Since the ultimate goal of screening is the improvement in patient quality of life [12], the examinees' values should be respected $[11,13]$ in the shared decision making process [14-16].

PSA overdiagnosis-related debates and reflections resulted in the development of patient decision aids (PtDAs) were developed to help patients make adequate screening decisions [16]. According to a systematic review published in 2014, the application of these tools reduced the PSA test rate by $13 \%$ (summary relative risk, $0.87 ; 95 \%$ confidence interval, 0.77 to 0.98 ; $\mathrm{n}=9$ ) [17]. Based on this result, it may be assumed that if the development and application of a PtDA for the shared decisionmaking process for thyroid cancer screening would contribute to counteracting the overdiagnosis of thyroid cancer. Against this background, this paper reports on the development and application of a PtDA for cancer screening.

\section{BODY}

\section{Definition of patient decision aids}

The International Patient Decision Aid Standards (IPDAS) Collaboration, which initiated official activities in 2003 [18,19], de- 
fines PtDA as "tools designed to help people participate in decision making about health care options." In other words, PtDA presents various options to patients in certain conditions to make well-informed final decisions from among possible options by weighing them according to their own personal value. From this active participation aspect, PtDAs are differentiated from educational materials to help patients better understand specific diseases or passive informed consent materials designed to obtain informed consent forms $[17,20]$.

\section{Contents of patient decision aids}

The contents of the PtDA developed by the American Society of Clinical Oncology [21,22] as tools for making decisions about the PSA test designed for the early detection of prostate cancer are divided in the following seven item clusters: (1) general introduction to the PSA test, (2) interpretation of the PSA test results, (3) possible options in the case of high PSA levels, (4) benefits and risks of the PSA testing, (5) personalized items for identifying individual values as decisional needs, (6) overall and final decision, and (7) reference materials. This exemplifies that a good PtDA presents a benefit-risk balance by providing disease information and allows systematic checking of the related elements that are likely to influence the final decision, concretizes individual value assessment levels, and gives examples of other cases with coaching throughout the stages of the decisionmaking process $[13,16,17,20]$.

\section{Development of patient decision aids}

All PtDAs developed worldwide to date are presented by countries in the clearinghouse system [14,20]. PtDAs on a variety of diseases have been developed in many different forms [14,23], and the current trendsetters are audiovisual materials and webbased programs for self-administrated tools that are designed to save time and medical personnel costs [13,20].

Table 1 outlines the purpose- and application-related usability

Table 1. Purposes of developing patient decision aids

\begin{tabular}{ll}
\hline \multicolumn{1}{c}{ Description } \\
\hline Do $\quad$ Improve patient decision quality \\
Reduce decision conflict \\
Increase participation in decision-making \\
Help patient to make a choice that is consistent with their own values \\
Improve people's knowledge regarding options \\
Reduce conflict related to feeling uninformed and unclear about \\
personal values \\
Don't Advise patients to choose one option over another \\
Intend to replace practitioner consultation \\
Intend to increase treatment adherence
\end{tabular}

Modified from O'Connor A. ACP J Club 2001;135:A11-A12 [13]; Stacey D, et al. Cochrane Database Syst Rev 2014;1:CD001431 [17]; Volk RJ, et al. BMC Med Inform Decis Mak 2013;13 Suppl 2:S1 [19]; Ng CJ, et al. Australas Med J 2013;6:95-99 [20]. of PtDAs extracted from the literature $[13,17,19,20]$. The main objectives of PDA development are to induce patients' active participation in the decision-making process, enhance the understanding of the disease in question, reduce the stress related to decision making by facilitating consistent decision-making according to individual value assessments, and improve quality of decision-making process. On the other hand, they should also prevent patients from choosing multiple options and should not replace medical counseling or tools intended to enhance treatment compliance.

To accomplish these objectives, PtDAs should be developed in compliance with international standards [14,24,25] using meticulous planning and implementation processes. The IPDAS Collaboration presented a PtDA development process consisting of the following five steps (Table 2) [24]. (1) Clarification of the necessity for development: after clarifying the need to develop a PtDA, development objectives are set and information materials about clinical decisional options and their results necessary for decision-making are reviewed. (2) Constitution of the development committee (expert panel): the development committee is divided into focus groups participating in the actual development and steering group managing conflicts of interest. (3) Compilation: the PtDA is drafted after determining the presentation frames such as audiovisual materials or computational systems [26]. (4) Alpha testing and feedback process: the draft PtDA is applied to patients and their reactions are converged and reflected upon draft review. (5) Beta testing: opinions of external experts and patients are reflected in the final review. The developed PtDA is implemented [13] and updated to reflect newly acquired insights or decisional factors [14]. Due to this highly complicated and time-consuming process [14], PtDA development is implemented under ongoing international cooperation under the flag of the IPDAS Collaboration [27].

\section{Application of patient decision aids}

A qualitative evaluation is essential for the efficient applications of existing PtDAs [14], so the IPDAS Collaboration presented a quality checklist [27], while the Canadian Ottawa Hospital Research Institute presented its own 19-item checklist [28]. On the other hand, there is a research need for investigation of

Table 2. Five steps of developing patient decision aids

\begin{tabular}{ll}
\hline Step & Main activity \\
\hline 1 & Scope problems \\
2 & Organize committee \\
3 & Develop draft \\
4 & Test usability \\
5 & Test feasibility \\
\hline
\end{tabular}

Modified from Coulter A, et al. BMC Med Inform Decis Mak 2013;13 Suppl 2:S2 [24]. 
Table 3. Effect sizes of decision aids for prostate cancer screening

\begin{tabular}{llc}
\hline Author [reference] & \multicolumn{1}{c}{ Decision aid type } & Difference size \\
\hline Frosch et al. [29] & Traditional & $9.1(\%)$ \\
Volk et al. [30] & Educational videotape & $10.9(\%)$ \\
Wolf et al. [31] & $\begin{array}{c}\text { Scripted informational } \\
\text { intervention }\end{array}$ & 0.8 (on five-point scale) \\
& .
\end{tabular}

Three results showing significant reductions in screening among selected articles in the systematic review conducted by Stacey D, et al. Cochrane Database Syst Rev 2014;1:CD001431 [17].

the actual effects of the PtDAs whose validity has been established. According to the systematic review conducted by Stacey et al. [17], the impacts of the three papers reporting on the statistically significant effects of PtDA as a decision-making tool for PSA testing as prostate cancer screening were $9 \%$ to $42 \%$ (Table 3) [29-31]. This wide gap is indicative of the fact that the effects of PtDAs vary considerably due to differences in the health insurance systems among countries, efforts of health care personnel to introduce PtDAs, and acceptance among patients and caregivers.

\section{CONCLUSIONAND SUGGESTIONS}

Our main clearinghouse search as of January 2015 yielded no results regarding thyroid cancer screening PtDAs with validated efficacy $[14,20,28]$. Even in the presence of PtDAs developed in foreign countries, the development of PtDAs matching the conditions of the local population is indispensable. The main reason is that they should reflect the natural history and local epidemiological data of the diseases in question [22,28]. Moreover, the cost value perceived by the locals (willingness to pay) should be reflected $[16,32]$ and the tool should be drafted in the individuals' native language [33]. This justifies the compelling need for Korean health care researchers to develop a Korean PtDA to solve the present dilemma of thyroid cancer overdiagnosis.

PtDA development should ideally be promoted and implemented by a public institution such as the Korean National Evidence-based Health Care Collaborating Agency [32] rather than by a small group of researchers. Its application will require expansion by a clearinghouse operation. Additionally, affiliation to activities in the IPDAS Collaboration is necessary to accumulate PtDA development and evaluation experiences [18]. In the future, for other clinical conditions requiring decision-making support due to medical uncertainty $[15,16,34,35]$ as well as thyroid cancer screening, the development of PtDAs tailored to the needs of Korean patients will reduce unnecessary medical resource expenditures [36,37] and inequity of inter-regional medical services [38]. Thus a good PtDA will contribute finally to quality enhancement of public health care [39].

\section{ACKNOWLEDGEMENTS}

This study was supported by 2013 Cancer Research Support Project from the Korea Foundation for Cancer Research (No. 2013-2).

\section{CONFLICT OF INTEREST}

The author has no conflicts of interest to declare for this study.

\section{SUPPLEMENTARY MATERIAL}

Supplementary material is available at http://www.e-epih.org/.

\section{REFERENCES}

1. Ahn HS, Kim HJ, Welch HG. Korea's thyroid-cancer "epidemic"-screening and overdiagnosis. N Engl J Med 2014;371:1765-1767.

2. Jung KW, Won YJ, Kong HJ, Oh CM, Lee DH, Lee JS. Cancer statistics in Korea: incidence, mortality, survival, and prevalence in 2011. Cancer Res Treat 2014;46:109-123.

3. Bae JM. Overdiagnosis: epidemiologic concepts and estimation. Epidemiol Health 2015;37:e2015004.

4. Ahn YO, Li ZM; KREEC Study Group. Cancer risk in adult residents near nuclear power plants in Korea - a cohort study of 1992-2010. J Korean Med Sci 2012;27:999-1008.

5. Bae JM. A case report about doubting a misconduction of publication by a third party based on the confusing ownership of databases. J Med Life Sci 2014;11:77-81 (Korean).

6. Welch HG, Black WC. Overdiagnosis in cancer. J Natl Cancer Inst 2010;102:605-613.

7. Etzioni R, Penson DF, Legler JM, di Tommaso D, Boer R, Gann PH, et al. Overdiagnosis due to prostate-specific antigen screening: lessons from U.S. prostate cancer incidence trends. J Natl Cancer Inst 2002;94:981-990.

8. Esserman L, Thompson I. Solving the overdiagnosis dilemma. J Natl Cancer Inst 2010;102:582-583.

9. Suh M, Choi KS, Lee YY, Jun JK. Trends in cancer screening rates among Korean men and women: results from the Korean National Cancer Screening Survey, 2004-2012. Cancer Res Treat 2013;45:8694.

10. Kramer KM, Bennett CL, Pickard AS, Lyons EA, Wolf MS, McKoy $\mathrm{JM}$, et al. Patient preferences in prostate cancer: a clinician's guide to understanding health utilities. Clin Prostate Cancer 2005;4:15-23.

11. Lee DW, Neumann PJ, Rizzo JA. Understanding the medical and nonmedical value of diagnostic testing. Value Health 2010;13:310314.

12. Gomella LG, Johannes J, Trabulsi EJ. Current prostate cancer treatments: effect on quality of life. Urology 2009;73:S28-S35.

13. O'Connor A. Using patient decision aids to promote evidence-based 
decision making. ACP J Club 2001;135:A11-A12.

14. Lenz M, Buhse S, Kasper J, Kupfer R, Richter T, Mühlhauser I. Decision aids for patients. Dtsch Arztebl Int 2012;109:401-408.

15. Bae JM. The clinical decision analysis using decision tree. Epidemiol Health 2014;36:e2014025.

16. Bae JM. Value-based medicine: concepts and application. Epidemiol Health 2015;37:e2015014.

17. Stacey D, Légaré F, Col NF, Bennett CL, Barry MJ, Eden KB, et al. Decision aids for people facing health treatment or screening decisions. Cochrane Database Syst Rev 2014;1:CD001431.

18. International Patient Decision Aid Standards Collaboration. What are patient decision aids? [cited 2014 Jan 8]. Available from: http://ipdas. ohri.ca/what.html.

19. Volk RJ, Llewellyn-Thomas H, Stacey D, Elwyn G. Ten years of the International Patient Decision Aid Standards Collaboration: evolution of the core dimensions for assessing the quality of patient decision aids. BMC Med Inform Decis Mak 2013;13 Suppl 2:S1.

20. Ng CJ, Lee YK, Lee PY, Abdullah KL. Health innovations in patient decision support: bridging the gaps and challenges. Australas Med J 2013;6:95-99.

21. American Society of Clinical Oncology Institute for Quality. Screening for prostate cancer with prostate-specific antigen (PSA) testing: American Society of Clinical Oncology Provisional Clinical Opinion [cited 2014 Jan 8]. Available from: http://www.instituteforquality.org/ screening-prostate-cancer-prostate-specific-antigen-psa-testing-american-society-clinical-oncology.

22. Basch E, Oliver TK, Vickers A, Thompson I, Kantoff P, Parnes H, et al. Screening for prostate cancer with prostate-specific antigen testing: American Society of Clinical Oncology Provisional Clinical Opinion. J Clin Oncol 2012;30:3020-3025.

23. Leatherman S, Warrick L. Effectiveness of decision aids: a review of the evidence. Med Care Res Rev 2008;65:79S-116S.

24. Coulter A, Stilwell D, Kryworuchko J, Mullen PD, Ng CJ, van der Weijden T. A systematic development process for patient decision aids. BMC Med Inform Decis Mak 2013;13 Suppl 2:S2.

25. Elwyn G, O'Connor AM, Bennett C, Newcombe RG, Politi M, Durand MA, et al. Assessing the quality of decision support technologies using the International Patient Decision Aid Standards instrument (IPDASi). PLoS One 2009;4:e4705.

26. Hirsch O, Keller H, Krones T, Donner-Banzhoff N. Acceptance of shared decision making with reference to an electronic library of decision aids (arriba-lib) and its association to decision making in patients: an evaluation study. Implement Sci 2011;6:70.
27. Elwyn G, O’Connor A, Stacey D, Volk R, Edwards A, Coulter A, et al. Developing a quality criteria framework for patient decision aids: online international Delphi consensus process. BMJ 2006;333:417.

28. Ottawa Hospital Research Institute. Patient decision aids [cited 2014 Jan 8]. Available from: http://decisionaid.ohri.ca/AZsearch.php.

29. Frosch DL, Bhatnagar V, Tally S, Hamori CJ, Kaplan RM. Internet patient decision support: a randomized controlled trial comparing alternative approaches for men considering prostate cancer screening. Arch Intern Med 2008;168:363-369.

30. Volk RJ, Spann SJ, Cass AR, Hawley ST. Patient education for informed decision making about prostate cancer screening: a randomized controlled trial with 1-year follow-up. Ann Fam Med 2003;1:2228.

31. Wolf AM, Nasser JF, Wolf AM, Schorling JB. The impact of informed consent on patient interest in prostate-specific antigen screening. Arch Intern Med 1996;156:1333-1336.

32. National Evidence-based Healthcare Collaborating Agency. The Asian Collaborative Study of cost-effectiveness in healthcare decision making; 2012 [cited 2014 Jan 8]. Available from: http://www.neca.re.kr/ center/researcher/report_view.jsp?boardNo $=\mathrm{GA} \&$ seq $=65 \& \mathrm{q}=626 \mathrm{f} 6$ 172644e6f3d4741 (Korean).

33. Charles C, Gafni A, Whelan T, O'Brien MA. Treatment decision aids: conceptual issues and future directions. Health Expect 2005;8:114125.

34. Bae JM. Academic strategies based on evidence-practice gaps. Hanyang Med Rev 2015;35:3-8 (Korean).

35. Stacey D, Samant R, Bennett C. Decision making in oncology: a review of patient decision aids to support patient participation. CA Cancer J Clin 2008;58:293-304 .

36. O'Connor AM, Llewellyn-Thomas HA, Flood AB. Modifying unwarranted variations in health care: shared decision making using patient decision aids. Health Aff (Millwood) 2004;Suppl Variation:VAR63VAR72.

37. Döring AC, Hageman MG, Mulder FJ, Guitton TG, Ring D; Science of Variation Group. Trigger finger: assessment of surgeon and patient preferences and priorities for decision making. J Hand Surg Am 2014; 39:2208-2213.

38. Reames BN, Shubeck SP, Birkmeyer JD. Strategies for reducing regional variation in the use of surgery: a systematic review. Ann Surg 2014;259:616-627.

39. O'Connor AM, Wennberg JE, Legare F, Llewellyn-Thomas HA, Moulton BW, Sepucha KR, et al. Toward the 'tipping point': decision aids and informed patient choice. Health Aff (Millwood) 2007;26:716-725. 